Artigo

\title{
Motivação no Setor Público como Ferramenta Estratégica de Gestão: desafios e reflexões
}

Motivation in the Public Sector as a Strategic Management Tool:
challenges and reflections

La Motivación en el Sector Público como Herramienta de Gestión Estratégica: retos y reflexiones

La Motivation dans le Secteur Public en tant qu'Outil de Gestion Stratégique : défis et réflexions

Anayana de Sousa Silva1 ${ }^{1}$ e José Natanael Fontenele de Carvalho ${ }^{2}$

\footnotetext{
${ }^{1}$ Graduada em Ciências Contábeis e em Geografia pela Universidade Federal do Piauí, Parnaiba, PI, Brasil.

E-mail: anayana-ss@hotmail.com

${ }^{2}$ Graduado em Ciências Econômicas, mestre e doutor em Desenvolvimento e Meio Ambiente pela Universidade Federal do Piauí, Teresina, PI, Brasil. Docente do Departamento de Ciências Econômicas e Quantitativas da Universidade Federal do Delta do Parnaíba, Parnaíba, PI, Brasil.

E-mail: natanaelfontenele@ufpi.edu.br
} 
Resumo A motivação humana sempre foi um grande desafio para as organizações, principalmente no que se refere a instituições públicas. A presente pesquisa tem como objetivo explorar a importância da motivação dentro das organizações públicas e como esta pode contribuir para o aperfeiçoamento dos resultados destas instituições. O estudo desenvolveu-se através de uma revisão bibliográfica sobre as principais teorias motivacionais e análise de pesquisas já realizadas sobre motivação no setor público. Reflexões acerca do tema indicam que fatores motivacionais intrínsecos, como a relevância e essência do trabalho, têm grande importância na motivação dos servidores, e dependendo do contexto pessoal do servidor, até mais do que fatores motivacionais extrínsecos, como remunerações, salários e benefícios. Dessa forma, pode-se afirmar que fatores motivacionais intrínsecos tem grande influência sobre os resultados organizacionais. Essa pesquisa contribui com os estudos sobre motivação no serviço público ao avaliar o impacto que os fatores motivacionais extrínsecos e intrínsecos têm sobre os níveis de satisfação profissional e consequentemente dos resultados das organizações públicas.

Palavras-Chave: Motivação; Administração Pública; Eficiência; Políticas Públicas; Cultura Organizacional.

Abstract Human motivation has always been a great challenge for organizations, especially with regard to public institutions. The present research aims to explore the importance of motivation within public organizations and how it can contribute to the improvement of the results of these institutions. The study was developed through a literature review on the main motivational theories and analysis of research already done on motivation in the public sector. Reflections on the subject indicate that intrinsic motivational factors, such as the relevance and the essence of the work, have great importance in the motivation of the servers, and depending on the personal context of the server, even more than extrinsic motivational factors such as remuneration, salaries and benefits. Thus, it can be affirmed that intrinsic motivational factors have a great influence on the organizational results. This research contributes to studies on motivation in the public service by evaluating the impact that extrinsic and intrinsic motivational factors have on the levels of job satisfaction and, consequently, the results of public organizations.

Keywords: Motivation; Public administration; Efficiency; Public Policy; Organisational Culture. 
Resumen La motivación humana siempre ha sido un gran reto para las organizaciones, especialmente cuando se trata de instituciones públicas. La presente investigación pretende explorar la importancia de la motivación en las organizaciones públicas y cómo puede contribuir a la mejora de los resultados de estas instituciones. El estudio se desarrolló mediante una revisión bibliográfica sobre las principales teorías de la motivación y el análisis de las investigaciones ya realizadas sobre la motivación en el sector público. Las reflexiones sobre el tema indican que los factores de motivación intrínseca, como la relevancia y la esencia del trabajo, tienen gran importancia en la motivación de los servidores, y dependiendo del contexto personal del servidor, incluso más que los factores de motivación extrínseca, como la remuneración, los salarios y los beneficios. Por lo tanto, se puede afirmar que los factores intrínsecos de motivación tienen una gran influencia en los resultados de la organización. Esta investigación contribuye a los estudios sobre la motivación en el servicio público al evaluar el impacto que los factores motivacionales extrínsecos e intrínsecos tienen en los niveles de satisfacción laboral y, en consecuencia, en los resultados de las organizaciones públicas.

Palabras Clave: Motivación; Administración Pública; Eficiencia; Políticas Públicas; Cultura Organizacional.

Resumé La motivation humaine a toujours été un défi majeur pour les organisations, surtout lorsqu'il s'agit d'institutions publiques. La présente recherche vise à explorer l'importance de la motivation au sein des organisations publiques et comment elle peut contribuer à l'amélioration des résultats de ces institutions. L'étude a été élaborée à partir d'une revue de la littérature sur les principales théories de la motivation et de l'analyse des recherches déjà menées sur la motivation dans le secteur public. Les réflexions sur ce thème indiquent que les facteurs de motivation intrinsèques, tels que la pertinence et l'essence du travail, ont une grande importance dans la motivation des serveurs, et selon le contexte personnel du serveur, même plus que les facteurs de motivation extrinsèques, tels que la rémunération, les salaires et les avantages. Ainsi, on peut affirmer que les facteurs de motivation intrinsèques ont une grande influence sur les résultats organisationnels. Cette recherche contribue aux études sur la motivation dans le service public en évaluant l'impact que les facteurs de motivation extrinsèques et intrinsèques ont sur les niveaux de satisfaction au travail et par conséquent sur les résultats des organisations publiques.

Mots-Clés: Motivation; Administration Publique; Efficience; Politique Publique; Culture Organisationnelle. 


\section{Introdução}

A motivação humana sempre foi um grande desafio para as organizações, principalmente no que se refere a instituições públicas. A compreensão dessa temática é de grande valia quando se busca a melhora dos resultados de uma organização, visto que a motivação é um fator que concorre diretamente com o bem-estar do servidor no ambiente de trabalho e na qualidade dos serviços por eles prestados. Para Bergamini (2008, citado por Pedroso e cols., 2012: 61), o estudo da motivação é aplicado a todas as áreas da atividade humana e é, em especial, a área reservada às organizações que emprega grande parte de seus esforços no intuito de poder compreender quais objetivos motivacionais são mais constantemente procurados no trabalho.

No ambiente organizacional, seja ele público ou privado, é notória a importância de uma eficiente gestão de pessoas, pois estas são os instrumentos capazes de aumentar a produtividade, melhorar a qualidade de um serviço e gerar lucro, tornando-se responsáveis pela sobrevivência das organizações. No âmbito da Administração Pública, a motivação é uma ferramenta estratégica na maioria das vezes ignorada pelos gestores, que não aproveitam a força e o êxito do trabalho realizado por seus funcionários. Em decorrência disso, a figura do funcionário público tornou-se estereotipada e generalista em nossa cultura, sendo visto como alguém que trabalha pouco e ganha muito, visão esta construída não só pelo comportamento histórico de alguns profissionais, mas também pelo descrédito de alguns órgãos da Administração pública com relação a essa força de trabalho.

No Brasil, a admissão de pessoas para atuar em órgão do setor público, com exceção de determinados cargos comissionados, é realizada mediante execução de concurso público, disposição prevista no inciso II do artigo 37 da Constituição Federal de 1988. Segundo Carvalho Filho (2001: 651) esse procedimento administrativo tem o objetivo "aferir as aptidões pessoais e selecionar os melhores candidatos ao provimento de cargos e funções públicas". No entanto, apesar do processo de seleção rigorosa, pautada na escolha dos melhores candidatos, a maioria dos órgãos da administração pública acaba não aproveitando o potencial de seus colaboradores e como consequência, há um comprometimento na qualidade dos serviços prestados.

Poucas Organizações Públicas se atentam ao comportamento de seus colaboradores ou manifestam interesse pelo nível de satisfação no seu ambiente organizacional e essa situação se agrava por conhecidas práticas patrimonialistas, marcadas pelo apadrinhamento político onde o processo de remuneração e distribuição de tarefas é atribuído a fatores subjetivos, como a amizade e a simpatia. No entanto, torna-se cada vez mais constante a exigência dos cidadãos por serviços de qualidade e, por conseguinte, $o$ setor público passa a pautar-se em uma gestão voltada para resultados.

O desempenho da Administração Pública presume atividade com pessoas e há, nesse contexto, uma relação mútua de interesses onde as pessoas trabalham dentro de organizações objetivando sua sustentabilidade e realização pessoal e as organizações, por sua vez, dependem das pessoas para obter resultados. As melhorias nos processos organizacionais provêm do comprometimento pessoal de seus colaboradores, dessa 
forma, denota-se que a motivação é um elemento fundamental para eficiência na gestão pública. Nesse contexto, surge a seguinte problemática: "como o processo de motivação pode se configurar como uma ferramenta estratégica de gestão no setor público"?

Os principais autores consultados nessa pesquisa foram Bergue (2014) e Robbins (2005) que trazem conceitos basilares para esse estudo, além de outros autores de pesquisas feitas sobre a temática como Pedroso (2012), Di Pietro (2014), Ferreira, Demutti e Gimenez (2010), entre outros, que trouxeram importantes contribuições para a elaboração deste trabalho. 0 artigo tem como objetivo geral compreender como a motivação pode se configurar como uma ferramenta estratégica de gestão no setor público. 0 estudo desenvolveu-se através de uma revisão bibliográfica sobre as principais teorias motivacionais e análise de pesquisas já realizadas sobre motivação no setor público.

0 artigo encontra-se estruturado em quatro tópicos, além dessa introdução. No segundo tópico aborda-se o Principio da Eficiência na Administração Pública, ressaltando sua importância como exigência da nova tendência mundial em Gestão Pública, voltada para atender os interesses da coletividade. No terceiro tópico, são destacados o conceito de motivação e as principais teorias motivacionais que podem ser aplicadas no âmbito do serviço público. No quarto tópico é analisada a aplicabilidade das teorias motivacionais no setor público. Por fim, apresentam-se as considerações finais sobre a pesquisa e as referências consultadas.

\section{Princípio da Eficiência na Administração Pública}

0 princípio da eficiência surgiu no ordenamento jurídico, de forma implícita, através do Decreto-lei 200/67, que dispõe sobre a organização da Administração Federal, estabelece diretrizes para a Reforma Administrativa e dá outras providências. Através desse decreto, toda atividade pública foi submetida ao controle de resultado (arts. $13 \mathrm{e}$ 25, V), o sistema de mérito foi fortalecido (art. 25, VII), a Administração Indireta ficou sujeita à supervisão ministerial quanto à eficiência administrativa (art. 26, III) e recomendou-se a demissão ou dispensa do servidor comprovadamente ineficiente ou desidioso (art. 100). No entanto, foi a Emenda Constitucional no 19, de 4 de Junho de 1998 que inseriu, de forma expressa, o princípio da eficiência entre os princípios constitucionais da Administração Pública, no caput de seu artigo 37.

Sobre esse princípio, Di Pietro (2014:84) afirma que:

O princípio da eficiência apresenta, na realidade, dois aspectos: pode ser considerado em relação ao modo de atuação do agente público, do qual se espera o melhor desempenho possível de suas atribuições, para lograr os melhores resultados; e em relação ao modo de organizar, estruturar, disciplinar a Administração Pública, também 
com o mesmo objetivo de alcançar os melhores resultados na prestação do serviço público.

A eficiência no setor público é uma exigência da nova tendência mundial em Gestão Pública, voltada para atender os interesses da coletividade de forma ágil e com resultados satisfatórios. Para que o princípio da eficiência seja concreto, é imprescindível que haja empenho por parte da Administração, não só de seus agentes, mas também de seus gestores. Neste sentido, a atuação administrativa deve ser comandada por pessoas compromissadas com a efetividade na prestação de serviços públicos, capazes de oferecer condições necessárias para que o aparelho estatal seja cada vez menos burocrático e mais moderno em sua estrutura e atuação. Os gestores públicos devem também capacitar e motivar seus agentes para que estes possam realizar suas atividades com agilidade e produtividade, uma vez que a falta de engajamento entre gestores e agentes acaba comprometendo a eficácia dos resultados da gestão.

\section{Motivação e Teorias Motivacionais}

"O estudo da motivação humana admite diferentes abordagens e perspectivas, fato que, por conseguinte, conduz a diferentes conceitos possíveis" (Bergue, 2014:19). Para Robbins (2005, citado por Bergue, 2014:19), "a motivação está associada a um processo responsável pela intensidade, pela direção e pela persistência dos esforços de uma pessoa orientados para o alcance de determinado propósito".

É importante destacar que a motivação varia de pessoa para pessoa, pois esta se baseia nos estímulos intrínsecos que levam os indivíduos a praticarem (ou não) determinados atos. Quando se fala em motivação, refere-se a um sentimento bastante particular, que vem do íntimo de cada pessoa, sendo assim pode-se deduzir que a motivação vai depender da cultura, dos valores ou do contexto em que a pessoa está inserida, originado diversos tipos de comportamentos.

$\mathrm{Na}$ análise da motivação, há diversas teorias desenvolvidas e propostas por autores reconhecidos que auxiliam no entendimento desse fenômeno. Cada uma dessas teorias possui uma forma peculiar de análise, no entanto, é importante destacar que nenhuma delas possui uma verdade absoluta sobre o tema.

Bergue (2014:24) elenca os principais estudos dessa temática sob o ponto de vista de abrangência e de pioneirismo, são eles a "Teoria da Hierarquia das Necessidades Humanas" de Abrahan Maslow, a "Teoria dos Dois Fatores" de Frederick Herzberg, a "Teoria da Expectativa (ou expectância)" de Victor Vroom e a "Teoria da Equidade" de Stacy Adams. 


\subsection{Teoria da Hierarquia das Necessidades de Abrahan Malow}

A Teoria da Hierarquia das Necessidades Humanas, formulada por Abrahan Maslow (2003, citado por Bergue, 2014:25), afirma que "existe uma hierarquia de necessidades humanas que orienta o comportamento das pessoas, cujos reflexos podem ser verificados inclusive no ambiente de trabalho". Segundo essa teoria, "as necessidades dos indivíduos obedecem a uma escala de valores, a serem alcançados conforme uma ordem de prioridades". Essa hierarquia é composta pelos seguintes estágios de necessidades: fisiológicas, de segurança, sociais, de status e, por fim, no estágio mais elevado, de autorrealização (Figura 1).

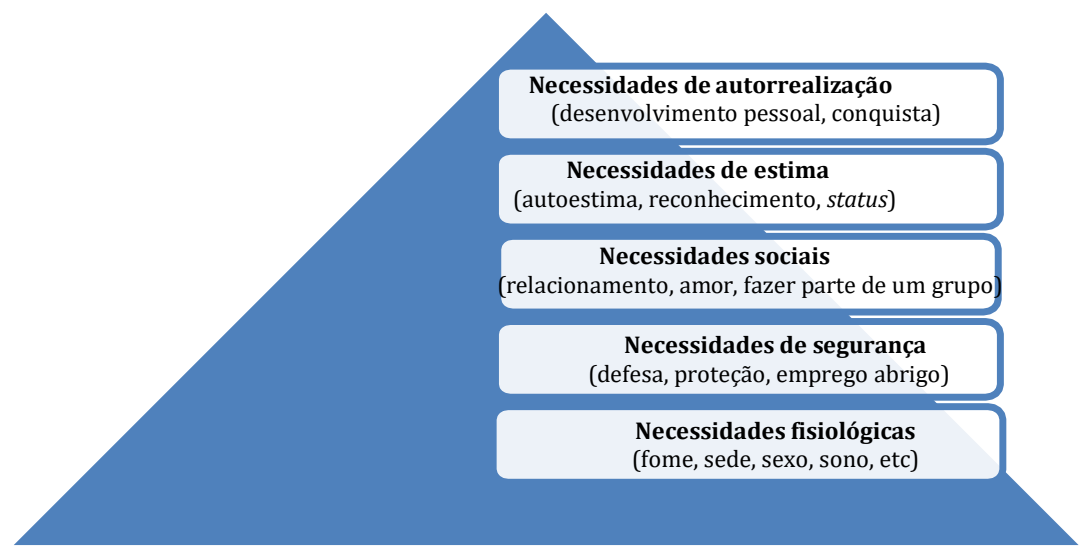

Figura 1: Pirâmide das necessidades humana Fonte: Bergue (2014) adaptado pelos autores.

Através dessa teoria, supõe-se que a partir do momento que uma pessoa satisfaz uma necessidade, outra necessidade passa a orientar sua motivação, buscando-se então meios constantes de satisfazê-la. É importante ressaltar também que a satisfação das necessidades parte sempre da mais básica para aquela considerada "superior" e a classificação das necessidades dentro dessas escalas é subjetiva, ou seja, depende da percepção e do valor atribuído por cada indivíduo.

Ferreira, Demutti e Gimenez (2010: 4) afirmam que as necessidades consideradas de nível baixo são atendidas a partir de fatores extrínsecos. Pede-se citar como exemplo de fatores extrínsecos nas organizações a remuneração, o local de trabalho adequado e a segurança no emprego. Para esses autores, acredita-se que quando as empresas pagam salários mais altos aos seus colaboradores, estes terão a maioria das suas necessidades básicas atendidas. Já as necessidades consideradas de nível alto, serão atendidas a partir de fatores intrínsecos, que, de acordo com Bergamini (2008, citado por Ferreira, Demutti \& Gimenez, 2010:4), refere-se à necessidade de autorrealização. Embora seja uma das teorias mais populares em se tratando de motivação humana, há muitas críticas no que tange a sua validade na prática, pois segundo Robbins (2002, citado por Ferreira, Demutti \& Gimenez, 2010:5) encontrou-se pouco embasamento empírico para a proposta de Maslow. 


\subsection{Teoria dos Dois Fatores de Frederick Herzberg}

$\mathrm{Na}$ "Teoria dos Dois Fatores" de Frederick Herzberg, diferente de Maslow, que analisou a satisfação das necessidades das pessoas em variados campos da vida, Herzberg estudou o comportamento e a motivação das pessoas especificamente dentro das empresas, com o objetivo de identificar os fatores que causavam a satisfação e a insatisfação dos empregados dentro do ambiente de trabalho. Baseado em sua pesquisa, Herzberg, então, dividiu os resultados observados em dois fatores: motivacionais e higiênicos.

Sobre essa teoria, Bergue (2014:27) expõe que:

Ao propor a teoria dos dois fatores, Herzberg argumentou que a compreensão do comportamento das pessoas no trabalho está diretamente relacionada aos fatores identificados com o cargo e a fatores relacionados com o contexto em que o cargo está inserido. Para esse autor, portanto, o contexto em que o cargo opera impacta tanto as propriedades do cargo quanto a percepção de satisfação geral do indivíduo no trabalho.

Em sua pesquisa, Herzberg propõe um conjunto de fatores que corresponde à satisfação (motivacionais) e outro conjunto de fatores que corresponde à insatisfação do indivíduo no trabalho (higiênicos). São considerados fatores de satisfação (motivacionais) aqueles relacionados ao conteúdo do cargo ou a natureza das atividades desenvolvidas, por outro lado, há os fatores que apenas previnem a insatisfação (higiênicos) que são aqueles determinados pelo ambiente que o indivíduo e ligados ao desempenho de suas atividades (Quadro 1).

Quadro 1: Análise de Herzber

\begin{tabular}{|cc|}
\hline FATORES MOTIVACIONAIS & FATORES HIGIÊNICOS \\
\hline Sentimento em relação ao seu cargo & Sentimento em relação à sua empresa \\
\hline $\begin{array}{c}\text { Intrínsecos ao cargo: quando presentes } \\
\text { geram forte motivação, mas quando estão ausentes } \\
\text { não geram grande insatisfação. }\end{array}$ & $\begin{array}{c}\text { Extrínsecos ao cargo: Quando ausentes geram } \\
\text { forte insatisfação, mas quando estão } \\
\text { presentes não geram grande motivação. }\end{array}$ \\
\hline O trabalho em si & As Condições de Trabalho \\
\hline Realização & Administração da Empresa \\
\hline Reconhecimento & Salário \\
\hline Progresso & Relação com o Supervisor \\
\hline Responsabilidade & Segurança no Trabalho \\
\hline Possibilidade de Crescimento & Relações Interpessoais \\
\hline
\end{tabular}

Fonte: Bergue (2014) adaptado pelos autores.

Sobre essa teoria, Rufino (2007: 39, citado por Domingos Júnior e Barbosa, 2016: 12) destaca que o oposto de satisfação não é a insatisfação, mas nenhuma satisfação, assim como o oposto de insatisfação não é a satisfação, mas sim nenhuma insatisfação, ou seja, satisfação e insatisfação não são consideradas sentimentos opostos. 


\subsection{Teoria da Expectativa(ou Expertância) de Victor Vroom}

Desenvolvida em 1964, essa teoria constitui-se como uma das mais reconhecida e bem aceita concepções sobre a motivação humana e faz uma conexão entre desempenho e recompensa, deduzindo que um indivíduo sente motivação para esforçar-se em fazer algo quando supõe que seu desempenho será bem avaliado e que, consequentemente, será recompensado. Segundo Bergue (2014: 31) "a motivação de uma pessoa para determinada ação está sujeita à probabilidade percebida de alcançar determinado resultado e do valor a ele atribuído".

Bergue (2014: 31) ainda expõe que, na teoria, um servidor tende a atuar com maior esforço no desenvolvimento de uma atividade à medida que percebe que o seu desempenho nessa atividade tende a ser melhor avaliada. Dessa forma, essa abordagem motivacional tem especial relação com o conceito de "avaliação de desempenho", temática recente e em ascensão na Administração Pública. Essa teoria envolve quatro variáveis, conforme Figura 2:

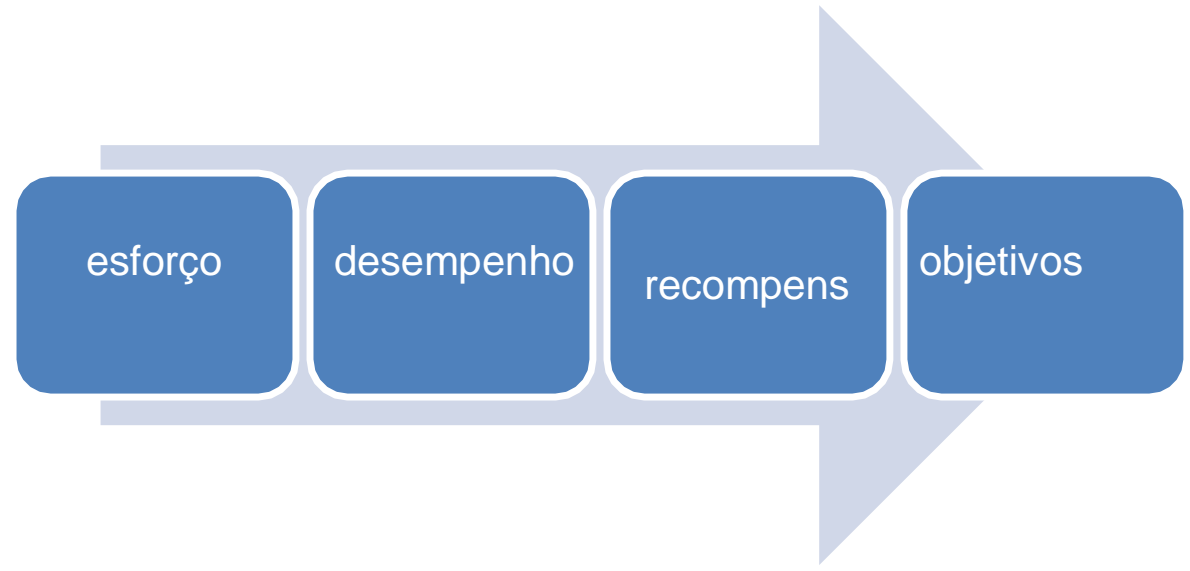

Figura 2: Variáveis da teoria da expectativa

Fonte: elaborado pelos autores (2019)

Robbins (2005: 148) ressalta que a teoria da expectativa evidencia três relações:

a) Relação Esforço-Desempenho: probabilidade, percebida pelo indivíduo, de que determinada quantidade de esforço levará ao desempenho.

b) Relação Desempenho-Recompensa: grau em que o indivíduo acredita que determinado nível de desempenho levará ao resultado desejado.

c) Relação Recompensas-Metas Pessoais: grau em que as recompensas organizacionais satisfazem as metas pessoais ou as necessidades do indivíduo e a atração que essas recompensas potenciais exercem sobre ele.

Para o referido autor (2005:148), essa teoria ajuda a entender porque alguns colaboradores não se sentem motivados em seu trabalho e fazem o mínimo necessário para manter o vínculo 
empregatício. Ao analisar as relações acima sugeridas e transformá-las em perguntas, o gestor pode obter as respostas que precisa para compreender os fenômenos comportamentais na organização e, a partir daí, formular políticas integradas de gestão de pessoas, conforme será analisado no tópico 4 deste trabalho.

\subsection{Teoria da Equidade de Stacy Adams}

Segundo essa teoria, o indivíduo é motivado mediante a condição de igualdade e percepção de justiça nas relações com outros colaboradores de uma mesma organização, dessa forma, se um indivíduo que se considera em condição de desigualdade acaba incorrendo em insatisfação ou tensão emocional. A teoria é portando chamada de "Teoria da Equidade" justamente por discutir a percepção de justiça, onde as recompensas devem ser proporcionais ao esforço de cada um. Para Robbins (2005: 145):

Quando essa comparação traz a percepção de que estas relações são iguais, dizemos que existe um estado de equidade. Nesse caso, percebemos nossa situação como justa - e achamos que a justiça prevalece. Quando percebemos que as relações são desiguais, experimentamos uma tensão de equidade. Quando vemos a nós mesmos como injustiçados, a tensão cria um sentimento de raiva; quando nos vemos com excesso de recompensa, a tensão cria o sentimento de culpa. J Stacy Adams sugere que esse estado de tensão negativa oferece motivação para uma ação corretora.

Para o mesmo autor (2005:146), a teoria da equidade torna-se ainda mais complexa quando se leva em consideração o ponto de referência escolhido pelo funcionário para fazer comparações, que para ele são:

a) Próprio-Interno: leva em consideração as experiências do funcionário em outra posição dentro da mesma empresa

b) Próprio-Externo: leva em consideração as experiências do funcionário em uma situação ou posição fora de sua atual empresa

c) Outro-Interno: leva em consideração as experiências do funcionário com outra pessoa ou grupo da mesma empresa

d) Outro-Externo: leva em consideração as experiências do funcionário com outra pessoa ou grupo de fora da empresa

\section{Motivação no Setor Público: aplicabilidade das teorias motivacionais}

Há um senso comum que a motivação e rendimento do servidor público são diferentes do servidor do setor privado, essa impressão pode ser atribuída ao foco de cada um desses setores 
possui. Enquanto as empresas privadas focam a obtenção de lucros e garantia de continuidade no mercado, o setor público visa a prestação de serviços à sociedade, neste sentido, o servidor público tem a função de exercer suas atividades em detrimento dos interesses da coletividade com seriedade, eficiência, prontidão, educação e transparência, sem fazer qualquer distinção e sem acometer qualquer indivíduo. No entanto, a forma como o servidor público realizará suas atividades no ambiente de trabalho dependerá da motivação que cada indivíduo tem, sendo esta, ligada a fatores internos ou externos e explicada através de várias teorias, algumas delas expostas nessa pesquisa.

Se levado em consideração a "Teoria das Necessidades" de Maslow, é possível deduzir que a satisfação das necessidades fisiológicas como alimento, água, abrigo, são fundamentais para o bem estar do indivíduo e essas necessidades são, normalmente, satisfeitas por fatores extrínsecos ao cargo, geralmente a remuneração. Somente depois da satisfação das necessidades básicas, o indivíduo parte para a satisfação das necessidades de realização pessoal, esta relacionada a fatores intrínsecos ao cargo. Se levado para o cenário público, pode-se concluir que, por essa teoria, a remuneração é um fator de motivação fundamental para o servidor, pois esta dá subsidio para satisfação das necessidades mais básicas do ser humano. Contudo, é importante salientar que as satisfações e necessidades variam de pessoa para pessoa, enquanto que para alguns as necessidades fisiológicas e de segurança são as primordiais a serem satisfeitas, para outros as necessidades de estima e realização pessoal são as mais motivadoras.

As prioridades dependerão da cultura e do contexto pessoal de cada indivíduo. Há situações, por exemplo, em que os funcionários tendem em aceitar remunerações menores, pois consideram a satisfação na prestação do serviço público como uma recompensa. Nessa perspectiva, pode-se afirmar que os servidores públicos podem ser seguramente motivados por fatores intrínsecos do trabalho, tais como o altruísmo, oportunidade de servir a sociedade, engajamento com os objetivos institucionais, senso de dever e prazer com o trabalho exercido. Dessa forma, cabe aos gestores conhecer bem a realidade da sua equipe, de modo a desenvolver os melhores métodos de gestão. Sobre a Teoria de Maslow, Morgan (1996, citado por CRUZ, Queiroz \& Lima, 2014:95) assinala que:

Tal teoria exerceu um grande impacto na área de gestão, tendo em vista que muitas organizações buscavam provocar a motivação dos funcionários apenas pelo dinheiro ou segurança no emprego. Abriu-se o espaço para novas práticas de gestão, de forma a criar condições de crescimento pessoal que, ao mesmo tempo, contribuíssem para que fossem atingidos os objetivos organizacionais.

Partindo para a "Teoria dos dois Fatores" de Herzberg, há os fatores motivacionais (intrínsecos ao cargo) que proporcionam satisfação no ambiente organizacional e há os fatores higiênicos (extrínsecos ao cargo) inibem a insatisfação. Analisando a literatura disponível, podese concluir que os fatores que produzem satisfação no trabalho são distintos dos que conduzem à insatisfação Por essa teoria pode-se deduzir que quando os fatores higiênicos são inadequados tais como salário, condições de trabalho, o servidor inevitavelmente é levado à insatisfação, mas isso não quer dizer que se esses fatores forem adequados o servidor seja induzido à satisfação, ou seja, neste caso a satisfação dependeria de outros fatores.

Em termos práticos, suponha-se que um servidor público exerça um cargo em um determinado órgão público, receba seu salário conforme determinado em lei, possua uma boa relação com seus supervisores, boas condições de trabalho, mas que, no entanto, não trabalhe em uma área de seu interesse, ou que não obtenha reconhecimento nem possibilidade de 
crescimento. Nesta situação, embora os fatores extrínsecos evitem a sua insatisfação no trabalho, eles não são suficientes para provocarem a satisfação no exercício de suas atividades. Com esta analogia, é possível concluir que os fatores motivacionais são os mais importantes quando se busca o aumento da produtividade do servidor público e consequentemente, dos resultados esperados pela organização.

Já a Teoria da Expectativa (ou expectância) de Victor Vroom, evidencia a relação esforçodesempenho / desempenho-recompensa / recompensas-metas pessoais, onde o desempenho do servidor está diretamente relacionado à expectativa deste com a possibilidade de reconhecimento e recompensa. Cabe salientar que expectância não tem a ver só com remuneração, tem a ver também com reconhecimento, pois os servidores que possuem a percepção dos benefícios ligados à sua colaboração, tendem a dedicar-se mais nas suas atividades.

Essa teoria pode ser bastante útil no âmbito do serviço público que, por não estar ligado à obtenção de lucro, como acontece no setor privado, o servidor público tende a esforçar-se mais no seu desempenho de atividades em detrimento dos interesses da coletividade e nos resultados da organização. Nesse contexto surge um conceito que vem sendo bastante utilizado pelos gestores da Administração Púbica: a avaliação de desempenho, que consiste em um acompanhamento sistemático do desempenho dos servidores dentro das organizações e serve como ferramenta para melhorar a gestão dos serviços públicos e das políticas públicas.

Robbins (2005: 148) ressalta que a teoria da expectativa ajuda a explicar porque muitos servidores não se sentem motivados no exercício de seus cargos. 0 mesmo autor afirma que isso fica mais evidente quando se analisam as três relações da teoria mais detalhadamente e propõe essa análise em forma de perguntas, que devem ser respondidas quando se imagina um servidor público no exercício de suas atividades. Um dos questionamentos poderia ser: "Se eu me esforçar ao máximo, serei reconhecido?" Dependendo do contexto organizacional em que se encontra o servidor, a resposta pode ser "não" por diversos motivos tais como: o órgão não dispõe de avaliação de desempenho, o servidor acredita que o gestor não o avaliará bem por motivos pessoais, entre outros. Outro questionamento que pode influenciar na motivação do funcionário, baseado nas ideias do mesmo autor, seria: "Se eu for reconhecido, serei recompensado por isso?" Muitos servidores acreditam que seu desempenho não gerará recompensas organizacionais, passando a considerar a relação "desempenho-recompensa" fraca e desmotivante, isso consequentemente acarretará baixo desempenho do servidor e afetará os resultados da organização.

E se o funcionário for recompensado? Robbins (2005: 148) ainda levanta a possibilidade de que o funcionário poderá se questionar: "As recompensas que eu receberei pelo meu desempenho são atraente?" Muitas vezes o servidor espera recompensas que a organização não dispõe, ou ainda espera uma coisa e a organização oferece outra. Nessa situação, o servidor acaba não alcançando suas expectativas e, portanto, não se sente motivado no exercício de suas funções. Assim, é importante que a organização disponibilize recompensas diretas associadas ao desempenho de seus servidores e garantir que essas recompensas sejam desejadas pelos indivíduos.

Outra teoria abordada nesta pesquisa que é bastante útil na análise da motivação do servidor púbico é a "Teoria da Equidade" de Stacy Adams. Essa teoria se baseia na ideia de que a motivação, o desempenho e a satisfação de um servidor dependem da avaliação subjetiva que ele faz sobre a comparação entre a recompensa que recebe e as recompensas que outras pessoas 
recebem pela mesma atividade (ou atividades parecidas), ou também pela comparação do que ele oferece à organização (esforço, competência, experiência) com o que ele recebe em troca (remuneração, benefícios, reconhecimento). Segundo essa teoria, quando um servidor entende que sofreu uma "injustiça", aumenta-se a tensão e consequentemente ocorre a mudança de comportamento. Essas situações são bastante comuns no ambiente público, principalmente quando se leva em consideração situações em que os servidores encontram-se em condição de iniquidade em virtude de favoritismo político. Nestes casos, é frequente o servidor ser levado ao descontentamento no ambiente de trabalho por julgar estar sofrendo "injustiça".

Para Silva (2013: 6):

A Teoria da Equidade no serviço público municipal dificilmente consegue ser aplicada, pois as pessoas normalmente não são remuneradas por sua capacidade ou por oportunidades que obtém através de plano de carreira ou tempo de exercício do cargo e sim por favoritismo, devido à simpatia ou militância em algum partido político onde os melhores postos de trabalho normalmente são designados aos cargos de confiança das lideranças políticas do município.

A citação acima ilustra bem o que acontece na maioria das organizações públicas brasileiras, onde a distribuição de cargos e função é feita baseada no favoritismo político, sem levar em consideração a meritocracia profissional de seus servidores. Ao reconhecer o mérito de seus colaboradores e os recompensar de forma devida, a organização assegura um ambiente pautado na equidade, proporcionando aos servidores a retribuição justa por seus esforços. Como consequência, a organização acaba promovendo a motivação em seus colaboradores que, por sua vez, empenham-se na melhoria de seu desempenho, otimizando os resultados da organização como um todo.

\section{Considerações Finais}

A motivação humana sempre foi um grande desafio para as organizações, principalmente no que se refere a instituições públicas. Diversas pesquisas têm sido realizadas e várias teorias têm buscado entender o funcionamento dessa força que leva as pessoas a agirem de determinada forma para alcançar seus objetivos. Para que o Estado alcance sua finalidade, é imprescindível que toda estrutura administrativa trabalhe pautada na eficiência e para que isso ocorra, é necessário haver motivação por parte dos servidores, pois esta constitui a energia motriz para que a organização atinja os resultados desejados. No entanto, motivar o servidor público não é uma tarefa fácil, principalmente quando se leva em consideração o contexto das organizações públicas onde a distribuição de cargos e tarefas é, em alguns casos, feita baseada no favoritismo político.

A busca das organizações públicas por maior rendimento e melhoras em seus resultados vem dando força a discussões sobre motivação e satisfação profissional no serviço público. A literatura analisada nesta pesquisa sugere que, no âmbito do serviço público, nem sempre a remuneração é o fator que mais motiva o servidor, por ser uma área voltada para o lado social, outros fatores podem ter mais importância no processo motivacional. Pode-se deduzir que fatores motivacionais 
intrínsecos, como a relevância e essência do trabalho, dependendo do contexto do servidor, são mais determinantes em seu comportamento do que fatores extrínsecos, como remunerações, salários e benefícios, por exemplo.

Oficialmente, não existe uma teoria motivacional universalmente aceita e aplicável a todos os casos, a motivação no trabalho é uma questão de critério pessoal, por isso muitos gestores encontram dificuldade em motivar as pessoas de uma organização de forma geral. Em organizações públicas podem ser encontradas diversas situações, desde servidores que possuem um cargo com alta remuneração, mas insatisfeitos com a natureza do trabalho e com baixa produtividade até servidores satisfeitos com o trabalho exercido, mas que recebem remuneração insuficiente para suas necessidades ou remuneração menor do que a recebida por colegas de mesmo nível. Diante dessa variabilidade de situações, recomenda-se que os gestores de pessoas no setor público busquem o equilibro entre fatores motivacionais extrínsecos e intrínsecos nas políticas de desenvolvimento da carreira dos servidores públicos.

A motivação é um tema bastante amplo e sua aplicação é de essencial importância no âmbito administrativo público, pois promove melhorias nos processos organizacionais internos e também no desempenho dos servidores. Através desta pesquisa, foi possível observar que a motivação do servidor público está diretamente ligada à satisfação deste com relação ao ambiente de trabalho. Essa relação ressalta a importância de o gestor tentar manter sempre uma boa percepção do perfil dos servidores, visando promover a motivação e satisfação destes, para que assim, possa-se alcançar a prestação de serviços de qualidade, induzindo a Administração Pública à eficiência. 


\section{Referências Bibliográficas}

Bergue, Sandro Trescastro. (2014). Comportamento organizacional. Florianópolis: Departamento de Ciências da Administração / UFSC; [Brasília]: CAPES : UAB.

Brasil. (1988). Constituição da República Federativa do Brasil de 1988. Brasília, DF, out 1988. Acessado em 06 de Dezembo de 2018, de: http://www.planalto.gov.br/ccivil 03/Constituicao/Constituicao.htm

Brasil. (1967, 25 de fevereiro). Decreto-lei $n^{\circ}$ 200. Dispõe sobre a organização da Administração Federal, estabelece diretrizes para a Reforma Administrativa e dá outras providências. Brasília, DF. Acessado em 06 de Dezembo de 2018, de: http://www.planalto.gov.br/ccivil 03/Decreto-Lei/Del0200.htm

Brasil. (1998, 4 de Junho). Emenda Constitucional no 19. Modifica o regime e dispõe sobre princípios e normas da Administração Pública, servidores e agentes políticos, controle de despesas e finanças públicas e custeio de atividades a cargo do Distrito Federal, e dá outras providências. Brasília, DF. Acessado em 06 de Dezembo de 2018, de: http://www.planalto.gov.br/ccivil 03/Constituicao/Emendas/Emc/emc19.htm

Carvalho, Judson Bezerra. (2015). Motivação no setor público: aplicação da ferramenta imst (inventário da motivação e do significado do trabalho) aos técnicos administrativos da faculdade de ciências da saúde do Trairi - FACISA. Monografia. Univerisdade Federal do Rio Grande do Norte, Natal.

Carvalho Filho, José S. (2015). Manual de Direito Administrativo. São Paulo: Atlas.

Chiavenato, Idalberto. (2003). Introdução à teoria geral da administração: uma visão abrangente da moderna administração das organizações. Rio de Janeiro: Elsevier

Cruz, Layse de Jesus., Queiroz, Napoleão dos Santos,. Lima, Glessia Silva de. (2014). Motivação, comprometimento e sofrimento no trabalho do setor público:Um estudo de caso em uma universidade pública de Sergipe. $R A D, 16(2), 87-116$. Acessado em 06 de Dezembo de 2018, de: https://revistas.pucsp.br/index.php/rad/article/viewFile/12031/16465

Di Pietro, Maria Sylvia Zanella. (2014). Direito administrativo. São Paulo: Atlas.

Domingos Júnior, Antenor P., \& Barbosa, Milka A. C. (2016). Motivação no Setor Público: um estudo com servidores do município de Ponto Novo - BA. Id on Line Revista Multidisciplinar e de Psicologia, 10(30), 08-24. Acessado em 06 de Janeiro de 2019, de: https://idonline.emnuvens.com.br/id/article/view/446/563

Eduardo, Angelita. (2009). Fatores motivacionais: Um diagnóstico segundo a teoria de Vroom na cooperativa de economia e crédito mútuo dos servidores públicos do Vale do Itajaí - BLUCREDI/SICOOB. Monografia. Universidade do Vale de Itajaí. Itajaí. Acessado em 06 de Janeiro de 2019, de: http://siaibib01.univali.br/pdf/Angelita\%20Eduardo.pdf

Ferreira, Andre., Demutti, Carolina Medeiros,. \& Gimenez, Paulo Eduardo Oliveira. (2010). A Teoria das Necessidades de Maslow: A Influência do Nível Educacional Sobre a sua Percepção no Ambiente de Trabalho. Em XIII SEMEAD Seminário em Administração.

Klein, Fabio Alvim,. \& Mascarenhas, Andre Ofenhejm. (2014). Motivação no Serviço Público: Efeitos Sobre a Retenção e Satisfação Profissional dos Gestores Governamentais. Em XXXVIII Encontro da Associação Nacional de Pós-Graduação e 
Pesquisa em Administração. Acessado em 06 de Janeiro de 2019, de: http://www.anpad.org.br/admin/pdf/2014 EnANPAD APB1613.pdf

Pedroso, Daniel Oesley de Oliveira e cols. (2012). Importância da Motivação dentro das Organizações. Revista Ampla de Gestão Empresarial, 1(1). 60-76.

Robbins, Stephen P. (2005). Comportamento Organizacional. São Paulo: Pearson Prentice Hall.

Silva, Francisco Deusivando Lemos. Aplicabilidade das teorias motivacionais na esfera pública: um estudo de caso em um órgão de tributação no município de Russas/CE. Revista Científica Multidisciplinar Núcleo do Conhecimento, 3(2), 415-426. Acessado em 06 de Janeiro de 2019, de: https://www.nucleodoconhecimento.com.br/administracao/motivacionais-na-esferapublica 